\title{
Diminished Quality of Life Among Women Affected by Ebola
}

\author{
Jessi E. Hanson \\ University of Pittsburgh \\ Alexis C. Decosimo \\ East Tennessee State University \\ Megan A. Quinn \\ East Tennessee State University
}

\begin{abstract}
This article analyzes data collected from Liberian women afflicted by the Ebola virus disease, survivors of the virus and noninfected persons living in Ebola-affected homes. This research is one of the first statistical analyses examining factors diminishing quality of life: negative experiences, stigma, and psychosocial symptoms among females affected by the virus after the outbreak. The research presents a thorough literature review, including research related to other infectious diseases like HIV/AIDS, to inform the gap in studies on Ebola's effects on quality of life. Women who are Ebola virus disease survivors demonstrate significant differences in stigma and psychosocial stress when compared to their female peers. This article attempts to broaden understanding of the conditions and mental health of women affected by Ebola.
\end{abstract}

Keywords: Ebola, psychosocial stress, stigma, negative events, programming, female adults, quality of life, living with disease, survivors

\section{Introduction}

In 2014, the hemorrhagic contagion of Ebola broke out in West Africa, affecting thousands of people. A study by the Liberian nonprofit organization, Renewed Energy Serving Humanity (RESH, 2015), provided initial findings of the quality of life of persons in households affected by the Ebola virus disease (EVD), including factors of negative events, stigma, and developed psychosocial symptoms because of the disease. This study particularly revealed the implications of EVD for female adults, whose lives can be drastically altered after the virus enters their household. In the present article, the data from the RESH study is examined in relation to mental health/trauma, stigma, and negative experiences. Additionally, quality of life factors identified by the health community as afflicting individuals living with infectious diseases, specifically with HIV/AIDS will be comparatively explored.

During the 2014/2015 Ebola outbreak, tens of thousands of households in West Africa were reported with confirmed or suspected cases of the virus. EVD cases are listed as suspect (demonstrating potential symptoms of EVD but have not yet tested positive) and confirmed/positive (have more than

Please address queries to: Jessi E. Hanson, Graduate School of Public and International Affairs, University of Pittsburgh. Email: jessi.hanson@ymail.com

We wish to acknowledge Ernest Garnark Smith Jr. and Prisie Badu from Renewed Energy Serving Humanity for leading data collection and data sharing, Meekie Glayweon and Victoria Zaway for research consultation, and Divya Nawale for research support editing. 
three to five symptoms of EVD and their blood test is positive for the virus in their system). The Zaire strain of Ebola was responsible for at least 28,600 cases (Chughtai, Barnes, \& Macintyre, 2016). The average survival rate ranged from 30 to $60 \%$, depending on a variety of factors including an individual's age, health status, and access to medical treatment. The exact number of EVD survivors in affected countries is unknown, as not all potential cases received treatment or were tested for confirmation of infection during the crisis. In Liberia, over 5,000 Liberians are officially registered as survivors of the disease, more than half of which are female; additionally, there are thousands of people living in households that had one or more confirmed or suspected EVD cases (Glayweon \& Hanson, 2015).

This article presents data collected by RESH from Liberian women affected by EVD: survivors of the virus and women living in EVD-affected homes. The analysis demonstrates the common negative experiences, stigma, and psychosocial symptoms reported and observed amongst the women. This study presents the factors affecting women with Ebola related to their diminished quality of life. It draws from literature related to HIV/AIDS as a reference point as to Ebola's effects on the quality of life for those affected by the disease. This report aims to contribute to the study of data collected on persons affected by EVD, focusing particularly on negative experiences, stigma, and psychosocial wellbeing. It is an initial assessment that aims to further the understanding of key factors afflicting affected populations, primarily women. This study also strives to draw potential connections to previous literature on infectious diseases to better inform health and support services for victims of Ebola.

\section{Method}

This article provides a statistical analysis of the RESH dataset from a June-July 2015 study, as well as a thorough literature review of the effects of disease on peoples' lives. After data collection conducted 3 months after the country was first declared Ebola free, RESH later shared a modified dataset of the study with the authors, presenting only nonidentifiable information of individual participants, for an external statistical analysis.

The data assessed are from 40 communities that were randomly selected from a government list of communities identified as EVD affected (or former hot zones), in three Liberian counties: Montserrado, Bomi, and Margbi. Data collection was conducted by nonclinician social workers and psychosocial workers of the Playing to Live program. Data collection occurred during the baseline for this program, and enumerators were trained and monitored by RESH clinical supervisors, in collaboration with the Government of Liberia (GoL) and support by UNICEF. A total of 144 female heads of households were purposely selected within each of the 40 evaluation sites. Priority selection of participants was first given to households with EVD survivors, secondly to households with confirmed EVD cases, and lastly to households residing within the hot zone, as recommended by the Liberian Ministry of Health (MoH) and the Ebola Survivors' Network. All participants were interviewed individually by enumerators using a list of survey questions. Captured personal information included age, education, household indicators, socioeconomic and marital status such as employment/income generation. Additional individual disease information included disease status, stigma by family or community members, at-risk behaviors, and psychosocial symptoms that they have experienced as a direct result of EVD. The interviews were conducted orally as many participants were illiterate. Enumerators were trained to first ask each survey question formally, and if the participant had difficulty understanding, to then restate the question colloquially in Liberian English. Enumerators worked in pairs with clinicians supervising interviews. 
Data collection for main quality of life factors, including negative events, stigma by family or community members, at-risk behaviors, and psychosocial symptoms (PSS), was verified through triangulating using methods of observation and interviews with other household adults. For instance, if a participant listed a PSS symptom like poor eating habits, the enumerator verified this by observing mealtime to see if the person ate normal amounts of food, or asked another household adult to verify the development of this symptom after Ebola entered the home/community. If a participant reported experiencing a form of stigma, the enumerator would observe for interaction with other family or adult members, or speak with another adult member to list a specific time or incident that they witnessed this stigma. If the symptom or stigma could not be confirmed through triangulation, it was deleted from the survey.

Many households affected by EVD are headed by women who are single, widowed, divorced, or abandoned by partners due to their EVD status. Of the 144 women sampled from EVD-affected communities, nine were confirmed EVD survivors (T1) making up the total population in the survey areas, 67 were noninfected persons whose household had one or more EVD case that often resulted in death (T2), and 77 were noninfected persons who had no EVD cases in their household but lived in proximity of outbreaks (T3).

The present study uses the literature review in tandem with the presentation of the 2015 EVD study findings. An overview of the literature review on the negative events, stigma, and psychosocial trauma experienced by persons affected by HIV/AIDS is presented as a guide for the discussion of Ebola's effects on individuals. The analysis further examines the common negative experiences reported by female EVD survivors before, during, and after the outbreak. The total population of EVD survivors in the EVD-affected communities was included in this study $(N=9)$ and is not a random sample of survivors. All participants were purposefully selected based on priority listing. The negative experiences of the survivors are compared to those of their peers, assessing for statistically significant mean differences and presenting ordinary least squares regression analysis, including factors such as income and childrearing. The next section presents the data on stigma experienced by both survivors and women living in EVD-affected homes who are noninfected persons. The final section reviews of the data on the psychosocial stress symptoms both self-reported and observed in participants.

\section{Results and Discussion}

\section{HIV/AIDS Literature}

Health literature shows that persons living with an infectious, life-threatening disease frequently are affected beyond the physical effects of their condition (Fife \& Wright, 2000; Goffman, 1963). There is limited published research asserting the effects of EVD on affected populations; however, the literature on other infectious viruses is more advanced and provides a foundation for assessing the relationships between disease and an individual's quality of life. Specifically, persons living with HIV/AIDS are affected by prevalent factors including traumatic events, mental illness, and stigmatization, which are associated with negative health outcomes. These studies linking mental health and negative experience with HIV/AIDS further provide insight to improving medical treatment protocols and support services for persons living with a chronic disease (Alonzo \& Reynolds, 1995; Stoskopf, Kim, \& Glover, 2001; Whetten, Reif, Whetten, \& Murphy-McMillan, 2008). Individuals diagnosed with HIV/AIDS, their family, and their friends frequently confront high rates 
of stigmatization by people with whom they interact such as their own family, neighbors, and coworkers (Alonzo \& Reynolds, 1995; Valdiserri, 2002).

There is an assumption that the aggressive and querulous nature of EVD may separate this hemorrhagic disease from other deadly infectious diseases such as HIV/AIDS. While there are distinctions in the nature of these disease types, they share notable similarities, including human-tohuman transmission through bodily fluid, no known cure, and incubation periods during which there are few to no symptoms and testing is difficult. A 2014 literature review, presented by Davtyan, Brown, and Folayan (2014), confirmed these similarities, and further concluded that HIV/AIDS and Ebola are present-day epidemics connected to social stigma, causing affected communities to face violence, isolation, and a reduced quality of life. Moreover, the findings from the present Liberia study show similar trends between disease diagnosis and the negative experiences with which victims and their families present. In parts of Africa, HIV/AIDS and EVD also frequently include misconceptions among impoverished populations, who tend to have limited education and may have less access to readily available awareness information and medical services. Scientific concepts of disease transmission and infection can further conflict with traditional spiritual beliefs that assert illness because of curses and divine fate. Additionally, preventative health protocols often clash with important traditional practices (Glayweon \& Hanson, 2015).

\section{Negative Experiences Before Ebola}

Liberian women often experienced trauma before the 2014/2015 Ebola outbreak. During the civil war, most Liberian women and girls were victims of horrific events. Sixty to seventy percent of females were either raped, lost family members, or fled violence as refugees. Most women lived in extreme poverty in the years after the war (OECD Development Centre, 2015; Toral, 2012). The women in the present study likely suffered from psychosocial stress and trauma that they experienced from the war and the recovery. No data was collected by the study before the outbreak, which would have captured trauma levels in women before EVD. When Ebola struck their communities, EVD survivors and their family members reported that they experienced emotions such as anxiety, fear, and flashbacks that they associated with wartime (Glayweon \& Hanson, 2015). This analysis acknowledges that most participants experienced trauma before EVD entered the country.

There is a cultural trend of not sharing war trauma stories. Only a few of the study participants made direct reference to negative experiences or traumatic events that they underwent during the war and recovery period. Further evaluation of trauma levels experienced by people before and after EVD particularly in post-war settings may better reveal these relationships and the impact on the individual, and inform supportive services.

\section{Negative Experiences During Ebola}

Numerous documentaries and studies captured the traumatic stories of individuals who were diagnosed positive for Ebola and were admitted into Ebola treatment units (ETUs). These pieces have helped identify the core issues affecting survivors, often qualitatively. A 2015 qualitative study identifies the mental distress amongst survivors discharged from an ETU (Rabelo et al., 2016). The study presents common experiences evidenced in quotes from focal groups of survivors facing trauma within the care units while sick. Further, it shows that their suffering continued even after discharged from treatment. Research such as in the present study and the work by UNICEF to 
capture survivors' stories help to communicate the need. Yet the quantitative narrative of the crisis is less known. There are few statistical analyses on EVD, and much less quantitative analysis of Ebola's impacts on people's mental health, stigma, and negative experience.

The MoH and the Ministry of Gender, Children, and Social Protection (MoGCSP) in Liberia identified women and older girls as particularly at risk to EVD due to the nature of its transmission. Liberian women may be more susceptible to infection due to traditional gender roles, such as tending sick people, leading ceremonial funeral preparations including body washing, and washing and cleaning of household items like clothing and dishes, which may be contaminated by the virus. More women suffered from EVD than men and were placed in ETUs.

At the outbreak climax, there were not enough ETU beds to meet the capacity of the sick people lying in wait to be saved. Inside the ETU, patients underwent severe physical, mental, and psychological trauma (Chertow et al., 2014; Rabelo et al., 2016). They recounted undergoing extreme physical pain from the virus, watching other persons suffering, with blood and other human fluids a common visual, and body bags a daily experience. One woman recounted that her physical pain felt as excruciating as being in labor for days (Glayweon \& Hanson, 2015).

Females are also at risk of sexual infection of EVD if their male partner is infected with the virus, or is a survivor and does not use proper protection, as scientific studies show that male semen can carry the virus for months after recovery (Christie et al., 2015; Deen et al., 2015). The present study primarily focused on interviewing participants about their experiences after EVD and less about their experiences before and during the crisis. We focus on literature to further inform the narrative based on the findings of the study.

Nearly $50 \%$ of the 144 participants' households from the 2015 study reported an EVD case, in which half the women spoke about the hardship of watching family members and neighbors suffering from the horrific symptoms of the disease. Throughout the crisis, misunderstanding and lack of awareness of the disease caused much of the population to believe Ebola did not exist or was propaganda by the government, and fear of stigma in contact cases (Nyenswah et al., 2015). Misconceptions about how this new disease functioned heightened fear and confusion amongst the general population, similar to when HIV/AIDS infected new areas. This was compounded by the fact that these two viruses spread by contact with bodily fluids, have no cure and are deadly (Davtyan et al., 2014).

In the early stage of the outbreak, many within the populace believed EVD was not real. Most symptoms were easily mistakable for those of other diseases (Goeijenbier, Van Kampen, Reusken, Koopmans, \& Van Gorp, 2014; Green, 2014). Many households avoided going to an ETU as they heard of inconsistent health services, such as nurses refusing to administer medicines. Cremation of the dead was also a traumatic experience (burning of dead bodies in ETUs). This new practice, originally implemented as a public health precaution to minimize contagion, defied traditional ceremonial burials and caused distress amongst families who could not properly mourn and bury their dead (Agusto, Teboh-Ewungkem, \& Gumel, 2015; Nyenswah et al., 2014).

As infected persons' symptoms progressed, female heads of household reported watching their loved ones struggle against death. Ebola incubation periods ranged from 2 to 21 days. Persons with probable or suspect Ebola often could not be touched for threat of infecting others. Women who could not help alleviate the pain of their beloved underwent emotional strain. Many died at home, while others were taken to ETUs in ambulances. Interviewed participants repeatedly made reference to 
the anxiety they felt at the sound of ambulances; in Liberia, there were few ambulances before the outbreak.

Another common negative experience among households with EVD cases (T1-T2) was the loss of their home and possessions immediately as a result of the disease. County Health Teams and MOH burial teams routinely sprayed disinfectant in and around contaminated homes, which destroyed many household items. Community members also often burned or disposed of possessions that patients with suspect or positive cases owned, such as clothing, bedding, and dishware, as means of preventing disease spread through touching infected items. Lost items were rarely replaced by those who destroyed them, and left survivors, many of whom were poor, unable to buy new ones. Some families were left with few to no mattresses, dishes or clothing after discharge, living in dire poverty. They also tracked all persons who had been in contact with probable and infected persons, which was also an integral part of preventing further spread (Nyenswah et al., 2015); however, those people whom had come into contact with sick persons often hid from the tracking teams in fear of being labeled as a possible case and being placed in quarantine. Patients discharged from ETUs were regularly given one-time stipends, and a supply of basic need items. This support was often reportedly not enough to cover the loss of victims. Some survivors were forced to relocate or were legally evicted from their homes (Glayweon \& Hanson, 2015).

In ETUs, survivors' individual stories were wrought with hardship. Often admitted for 3 weeks in quarantine, infected patients had minimal contact with the outside. They were stripped of their personal possessions, and then assigned to beds next to other patients in similar stages of the disease. Qualitative research captured the difficult environment in the ETU (Rabelo et al., 2016), often described as chaotic and frightening. Healthcare workers wore protective gear and masks. There were frequently not enough workers for the number of patients. Survivors reported waiting in agony for hours for help. They lay next to dead bodies waiting for later removal. Patients fought extreme symptoms including high fevers and symptoms (Goeijenbier et al., 2014), similar to cholera. Some survivors reported feeling strengthened by healthcare workers and volunteer psychologists, who counseled them, prayed with them, and encouraged them to fight on. Upon discharge, survivors often were given used clothing. There was a celebration with ETU staff of their discharge. Family and friends greeted survivors to take them home. However, upon departure, they all learned who of their beloved were dead. Health workers avoided informing interned patients undergoing treatment of family who had passed away; patients who found out their relations had died often suffered depression which lowered their own chances at recovery. For some discharged persons, no one was left (Glayweon \& Hanson, 2015).

\section{Negative Experiences After Discharge}

Upon returning to their communities, survivors (T1) faced additional negative experiences. Survivor participants reported finding their homes looted or their possessions destroyed. A church member wearing the survivor's dress ironically greeted one survivor, returning to her community; the church member claimed the county burial team burned all the survivor's things. Discharged patients also tended to face the sudden experience of being isolated from family and friends. People often avoided those who were discharged from ETUs and their families out of fear and misconception either that they likely still carried the disease or related to local spiritual and cultural beliefs prevalent in West Africa that these persons had the misfortune to be cursed. Spiritual beliefs are often associated with traditional tribal religious and cultural practices. Health issues like illness often are attributed to spiritual causes colloquially labeled as dark magic or ill fortune. 
Survivors (T1) and women from EVD-affected homes (T2) reported feeling stigma in public, including acts of public shaming. Survivors were instructed by health workers to avoid sexual contact for several months after discharged as EVD remained in the body such as in semen (Christie et al, 2015; Deen et al., 2015). There was confusion as to how they could be labeled "EVD free" yet still carried the disease, causing emotional confusion and likely loss of self-esteem. Some women worried that they may be infertile due to suffering Ebola.

\section{Income}

In Liberia, females historically face high levels of gender inequality and socio-economic disparities, including lower rates of education, employment, and income generation than men, according to the United Nations Development Programme's (2015) Human Development Report. The 16-month crisis halted much of the economy; $90 \%$ of the female participants reported being unemployed. Some EVD survivors (T1) felt their disease status negatively affected their ability to make money. Following the end of the crisis, the MoH/MoGCSP worked with key agencies to ensure priority was given to hire survivors as voluntary program workers such as in ETUs. Participants who were survivors had a higher frequency of working compared to their peers, although this difference was not statistically significant. Survivors' income was often unstable. This is likely due to issues of timely pay during the emergency. Additionally, their jobs were typically temporary and ended with the crisis.

Excluding two outlier incomes of over US $\$ 50 /$ day, the average daily household income of the 144 participants was US $\$ 2.61$. However, nearly $70 \%$ of all the women reported their last daily income as US $\$ 0$. Table 1 shows that survivors made US $\$ 1.09$ per day less than their peers despite their temporary employment. The difference between incomes was not significant between survivors and noninfected persons, yet this may be due to the small number of survivors in the sample as demonstrated in the effect size. Further demonstrated in Table 2, the effect of being an EVD survivor and/or living in an EVD-affected household yielded no significant effect on the outcome variables of daily income.

Table 1: Negative Experience Factors on Income and Raising Children Among Female Adults Ebola Virus Disease (EVD) Survivors (T1) Compared to Peers, in Liberian EVD-Affected Communities

\begin{tabular}{lccc}
\hline & Survivors (T1) & Peers & Difference \\
& $M, S E, S D$ & $M, S E, S D$ & $M, S E,[\mathrm{CI}]$, \\
Factor & {$[\mathrm{CI}], N$} & {$[\mathrm{CI}], N$} & $t$ Value, Cohen's $d$ \\
\hline $\begin{array}{l}\text { Daily income } \\
\text { (US\$) }\end{array}$ & $1.59,0.70,2.12$ & $2.68,0.66,7.66$ & $1.09,2.57,[-3.98,6.17]$, \\
& {$[-0.46,3.22], 9$} & {$[1.37,4.0], 134$} & $0.43,0.15$ \\
Adult-child ratio (\# of & $1.9,0.52,1.4$ & $1.5,0.09,0.95$ & $-0.39,0.36,[-1.10,0.32],-$ \\
children per 1 adult) & {$[0.7,3.1], 8$} & {$[1.4,1.7], 126$} & $-1.09,-0.40$ \\
\hline
\end{tabular}

Note. $\mathrm{CI}=$ confidence interval.

${ }^{*} p<.1 .{ }^{* *} p<.05 .{ }^{* * *} p<.01$. 


\section{Childcare}

The HIV/AIDS epidemic in Africa and other parts of the world led to the development of a new categorical status for orphaned and vulnerable child affected by the disease. Numerous countries like Kenya and Tanzania have a heavy burden on surviving adults affected by HIV/AIDS to raise orphaned or abandoned children (Cluver, Gardner, \& Operario, 2007; Evans, 2005; Nyambedha, Wandibba, \& Aagaard-Hansen, 2003). Similarly, a major concern from the Ebola crisis was that the same burden befell victims of EVD. During the crisis, survivors and families affected by EVD reported to GoL the added responsibility of taking on adopted children of family and neighbors who had died of virus when no other direct family was available. GoL policy enforced that children be placed with blood relatives over persons who were not direct kin. Some household groups were broken up multiple times, creating distress for some women who had formed bonds with adopted children who were returned to family (Fowler et al., 2014; Glayweon \& Hanson, 2015).

Table 2: Ordinary Least Squares Regression Analysis of Income and Childrearing Among Liberian Females Affected by Ebola Virus Disease (EVD)

\begin{tabular}{lcccccc}
\hline & \multicolumn{3}{c}{ Daily Income } & \multicolumn{3}{c}{ Adult-Child Ratio } \\
\cline { 2 - 6 } Variables & Model 1 & Model 2 & Model 3 & Model 4 & Model 5 & Model 6 \\
\hline EVD survivor & -2.03 & -2.01 & & 0.25 & 0.20 & \\
& $(1.87)$ & $(1.71)$ & & $(0.51)$ & $(0.51)$ & 0.20 \\
Living in EVD HH & -0.07 & & 0.04 & 0.21 & & $(0.17)$ \\
& $(1.48)$ & & $(1.43)$ & $(0.18)$ & & 0.00 \\
Age & -0.04 & -0.04 & -0.04 & 0.00 & 0.00 & $(0.01)$ \\
& $(0.03)$ & $(0.04)$ & $(0.03)$ & $(0.01)$ & $(0.01)$ & $-0.10^{*}$ \\
Education & -0.21 & -0.20 & -0.19 & $-0.10^{*}$ & $-0.11^{*}$ & $(0.06)$ \\
& $(0.32)$ & $(0.33)$ & $(0.32)$ & $(0.06)$ & $(0.06)$ & $(0.06)$ \\
Working & $7.89^{* * *}$ & $7.89^{* * *}$ & $7.81^{* * *}$ & 0.04 & 0.03 & 0.05 \\
& $(2.68)$ & $(2.65)$ & $(2.69)$ & $(0.28)$ & $(0.28)$ & $(0.27)$ \\
Adult-child ratio & -0.47 & -0.47 & -0.49 & & & \\
& $(0.36)$ & $(0.35)$ & $(0.34)$ & & & -0.08 \\
Fixed effects & 3.14 & 3.14 & 3.08 & -0.08 & -0.07 & -0.08 \\
Interlocation: & $(2.71)$ & $(2.61)$ & $(2.68)$ & $(0.18)$ & $(0.18)$ & $(0.17)$ \\
County) & $-1.45^{* *}$ & $-1.46^{* *}$ & $-1.37^{* * *}$ & -0.10 & -0.05 & -0.11 \\
& $(0.66)$ & $(0.62)$ & $(0.65)$ & $(0.28)$ & $(0.29)$ & $(0.28)$ \\
Constant & $4.31^{* *}$ & $4.25^{*}$ & $4.04^{* *}$ & $1.53^{* * *}$ & $1.74^{* * *}$ & $1.57^{* * *}$ \\
& $(2.11)$ & $(2.30)$ & $(2.02)$ & $(0.44)$ & $(0.46)$ & $(0.44)$ \\
Observations & & & & & & \\
$R^{2}$ & 124 & 124 & 124 & 125 & 125 & 125 \\
Adjusted $R^{2}$ & 0.12 & 0.12 & 0.11 & 0.06 & 0.05 & 0.05 \\
\hline
\end{tabular}

Note. $\mathrm{HH}=$ household.

${ }^{*} p<.1 .{ }^{* *} p<.05 .{ }^{* * *} p<.01$. 
There was the common perception by emergency responders that in EVD-affected households, surviving adults had more children to care for than households where no one died of Ebola. Yet this assumption may be faulty. The study finds that after the crisis, women affected by EVD tended to have the same average adult-child ratio as their community peers whose homes did not have EVD. Survivor households had an average ratio of one adult per nearly two children, while nonsurvivor households had 1:1.5. As shown in Table 2, we further regress the effect of being an EVD survivor and/or living in an EVD-affected household on the dependent variable of adult-child ratio, for which both independent variables' effects show to be not significant; however, this yields a problematic interpretation due the small sample size of survivors. A larger sampling in future research may provide more conclusive results.

HIV/AIDS literature on households living with the disease demonstrate psychological and behavioral distress that adults raising affected children face and the need for them to have supplemental support to cope (Cluver et al., 2007; Evans, 2005; Nyambedha et al., 2003). The need for programmatic support for orphans and vulnerable children, and their caregivers has been identified as vital for recovery, particularly in Liberia after the outbreak (Abramowitz et al., 2015). In several EVD-affected homes, there were extreme instances of one adult per five children. There remain outlying cases of female survivors and female heads of households affected by EVD who care for a large number of children.

\section{Stigmatization}

Various illnesses have been historically connected to stigma, or the inclusion of stigma within a social category with the outcome of a "spoiled identity" that distances the person from others (Fife \& Wright, 2000; Goffman, 1963). Stigmatization is a social construct, and may be defined as the undesirable or discrediting attribute that an individual possesses that reduces the individual's status within the perspective of his/her society (Brown, Trujillo, \& Mcintyre, 2001; Davtyan et al., 2014; Goffman, 1963; Preston, D'augelli, Kassab, \& Starks, 2007; Whetten et al., 2008). Fife and Wright (2000) stated that stigma may include being socially rejected, ostracized, isolated, shamed, or treated poorly. More recently, HIV/AIDS research identified stigma as the individual's anxiety or worry of experiencing negative attitudes or discrimination as a result of disclosure of their HIV status by others. Whetten et al. (2008) reviewed the effects of HIV/AIDS and referenced nine studies identifying the harmful effects of experienced and perceived stigma among people due to their disease-status.

There is growing health research that recognizes the similarities between the stigma directed towards persons affected by HIV/AIDS and persons affected by EVD. Linkages include the lifethreatening nature of both diseases, as well as the misinformation and misconceptions around the virus, which cause particularly are frequent amongst affected groups. The differences between the viruses including the mortality rates, modes of transmission, timespan of infection are noted, however stigma against affected persons remains similar and disturb the quality of life (Davtyan et al., 2014). At the initial phase of the EVD outbreak in West Africa, stigma was quickly recognized as a public health and social issue. Instances of violence against suspected cases and persons who survived EVD were reported. Safety issues and negative community response often were issues due to a poor understanding of how the disease spread (Abramowitz et al., 2015). Public messaging campaigns at the local and national level attempted to present accurate information to the general population, however it was slow and limited. The research by Daytyan et al. (2014) further concluded that while the spread of HIV/AIDS has a longer history, there are key lessons learnt from this 
pandemic, which may be applied to EVD, especially to reduce and prevent stigma against those who become infected, their families, and friends. Yet first, the development and response community must better understand the nature of the stigma that can erupt in an outbreak.

The 2015 Liberia study by RESH captured the stigma that female EVD survivors (T1), heads of household of EVD-affected homes (T2), and heads of households with no EVD cases (T3) reported experiencing as a direct result of EVD. The present external analysis examined the frequency of experiencing stigma by family and community, first for EVD survivors (T1) compared to their peers (presented in Table 3), and secondly of heads of households affected by EVD who did not have the disease (T2), presented in Table 4. Lastly, the authors regressed the effects of both variables on stigma (Table 5).

Table 3: Stigma Amongst Female Adults Who Are Ebola Virus Disease (EVD) Survivors (T1) Compared to Peers, in Liberian EVD-Affected Communities

\begin{tabular}{|c|c|c|c|c|c|c|}
\hline \multirow[b]{2}{*}{$\begin{array}{l}\text { Negative } \\
\text { Factor }\end{array}$} & \multicolumn{2}{|c|}{ Peers $(\mathrm{N}=135)$} & \multicolumn{2}{|c|}{ Survivors $(\mathrm{T} 1 ; \mathrm{N}=9)$} & \multirow[b]{2}{*}{$\begin{array}{c}\text { Pearson's } \\
\chi^{2}\end{array}$} & \multirow{2}{*}{$\begin{array}{c}S E \\
\text { Fisher's } \\
\text { Exact (One- } \\
\text { Sided) }\end{array}$} \\
\hline & Frequency & $\begin{array}{l}\text { Expected } \\
\text { Frequency }\end{array}$ & Frequency & $\begin{array}{l}\text { Expected } \\
\text { Frequency }\end{array}$ & & \\
\hline $\begin{array}{l}\text { No community } \\
\text { stigma }\end{array}$ & $66 \%$ & $64 \%$ & $33 \%$ & $64 \%$ & & \\
\hline $\begin{array}{l}\text { Experienced } \\
\text { community } \\
\text { stigma }\end{array}$ & $34 \%$ & $36 \%$ & $67 \%$ & $37 \%$ & & \\
\hline Difference & & & & & $3.89^{* *}$ & $0.07(0.06)$ \\
\hline $\begin{array}{r}\text { No family } \\
\text { stigma }\end{array}$ & $89 \%$ & $86 \%$ & $44 \%$ & $6 \%$ & & \\
\hline $\begin{array}{l}\text { Experienced } \\
\text { family } \\
\text { stigma }\end{array}$ & $11 \%$ & $14 \%$ & $56 \%$ & $14 \%$ & & \\
\hline Difference & & & & & $13.94^{* * *}$ & $0.003(0.003)$ \\
\hline
\end{tabular}

Note. For $\chi^{2: * *} p<.05 .{ }^{* * *} p<.01$.

The interview differentiated between the stigmas that individuals felt from their family and from members of their community to assess for levels of significance. Enumerators verified the selfreported stigmatization by later observing for demonstrated acts against the individuals that could confirm their feeling of stigma, as well as for asking for instances in which they experienced acts of stigma and confirming these events through asking other adult family members or friends.

\section{Community Stigma}

Conducting a stratified statistical analysis, all three tiers included large percentages of women who reported experiencing EVD-instigated stigma by community members. This includes T3 women who come from former outbreak communities, which may be attributed to feeling a sense of stigma likely by the outer community. Table 3 demonstrates that $67 \%$ of EVD survivors reportedly experienced community stigma compared to their peers' average frequency rate of $34 \%$. While this difference is significant, due to the low sample size of survivors, these results should be interpreted with caution. Comparatively, as shown in Table 4, 45\% of women living in Ebola-affected households who never 
had the virus (T2) experienced stigma, which was also significantly more than their peers particularly women in T3 who lived in homes with no EVD case history. Women living in EVD affected homes including survivors often reported to the $\mathrm{MoH}$ incidences where community members tried to illegally evict them or pressured them to move out of the community (Glayweon \& Hanson, 2015). After discharge from ETU, several of the study participant survivors in fact were forced to relocate their families to new areas where their disease status was unknown by their neighbors.

Table 4: Stigma Among Female Adults Living in Ebola Virus Disease (EVD)-Affected Homes Who Are Noninfected Persons (T2) Compared to Peers, in Liberian EVD-Affected Communities

\begin{tabular}{|c|c|c|c|c|c|c|}
\hline \multirow[b]{2}{*}{$\begin{array}{l}\text { Negative } \\
\text { Factor }\end{array}$} & \multicolumn{2}{|c|}{ Peers $(\mathrm{N}=77)$} & \multicolumn{2}{|c|}{ T2 Females $(\mathrm{N}=67)$} & \multirow[b]{2}{*}{$\begin{array}{c}\text { Pearson's } \\
\chi^{2} \\
\end{array}$} & \multirow{2}{*}{$\begin{array}{c}S E \\
\text { Fisher's } \\
\text { Exact (One- } \\
\text { Sided) } \\
\end{array}$} \\
\hline & Frequency & $\begin{array}{l}\text { Expected } \\
\text { Frequency }\end{array}$ & Frequency & $\begin{array}{l}\text { Expected } \\
\text { Frequency }\end{array}$ & & \\
\hline $\begin{array}{l}\text { Not } \\
\text { experienced } \\
\text { community } \\
\text { stigma }\end{array}$ & $71 \%$ & $64 \%$ & $55 \%$ & $64 \%$ & & \\
\hline $\begin{array}{l}\text { Experienced } \\
\text { community } \\
\text { stigma }\end{array}$ & $29 \%$ & $36 \%$ & $45 \%$ & $36 \%$ & & \\
\hline Difference & & & & & $4.07 * *$ & $0.06(0.03)$ \\
\hline $\begin{array}{l}\text { Not } \\
\text { experienced } \\
\text { family } \\
\text { stigma }\end{array}$ & $87 \%$ & $86 \%$ & $85 \%$ & $86 \%$ & & \\
\hline $\begin{array}{l}\text { Experienced } \\
\text { family } \\
\text { stigma }\end{array}$ & $13 \%$ & $14 \%$ & $15 \%$ & $14 \%$ & & \\
\hline Difference & & & & & 0.11 & $0.81(0.46)$ \\
\hline
\end{tabular}

Note. For $\chi^{2: * *} p<.05$.

Using the logistic regression model presented in Table 5 that includes fixed effects on interlocation (county) and controlling for all other variables, we assessed the effects of the independent variables of being an EVD survivor and/or living in an EVD-affected home on the outcome of community stigmatization. Models 1-3 correspond to the y variable of community stigma, while Models 4-6 instead regress on the outcome of family stigmatization.

Interpreting Table 5, Model 1, if a person is an Ebola survivor, the odds of experiencing community stigma (versus no community stigma) increase by a factor of 3.23. Specifically, the marginal effect of being an Ebola survivor is $64 \%$, indicating the odds of experiencing community stigma holds truer for survivors than their peers. 
Hanson, Decosimo, \& Quinn, 2016

Table 5: Logistic Regression Analysis of Stigma Experienced by Females Affected by Ebola Virus Disease (EVD)

\begin{tabular}{lcccccc}
\hline \multirow{2}{*}{ Variable } & \multicolumn{3}{c}{ Community Stigma } & \multicolumn{3}{c}{ Family Stigma } \\
\cline { 2 - 7 } & Model 1 & Model 2 & Model 3 & Model 4 & Model 5 & Model 6 \\
\hline EVD survivor & 3.23 & $2.61^{*}$ & & $4.17^{* * *}$ & $3.88^{* * *}$ \\
Living in EVD HH & $(2.20)$ & $(1.50)$ & & $(1.54)$ & $(1.48)$ & \\
& $1.50^{* * *}$ & & $1.31^{* * *}$ & 0.76 & & 0.36 \\
Age & $(0.50)$ & & $(0.48)$ & $(0.64)$ & & $(0.57)$ \\
& 0.03 & 0.02 & 0.03 & 0.02 & 0.02 & 0.01 \\
Education & $(0.02)$ & $(0.02)$ & $(0.02)$ & $(0.03)$ & $(0.03)$ & $(0.03)$ \\
& -0.20 & -0.20 & -0.19 & $-0.40^{*}$ & $-0.42^{* *}$ & $-0.36^{*}$ \\
Working & $(0.13)$ & $(0.13)$ & $(0.13)$ & $(0.22)$ & $(0.21)$ & $(0.19)$ \\
& 0.79 & 0.79 & 0.91 & 0.25 & 0.25 & 0.41 \\
Adult-child ratio & $(0.83)$ & $(0.66)$ & $(0.81)$ & $(0.93)$ & $(1.00)$ & $(0.90)$ \\
& -0.42 & -0.29 & $-0.34^{*}$ & $-0.46^{*}$ & $-0.40^{*}$ & -0.26 \\
Fixed effects & $(0.26)$ & $(0.23)$ & $(0.20)$ & $(0.25)$ & $(0.23)$ & $(0.28)$ \\
Interlocation: & $-3.62^{* * *}$ & $-3.44^{* * *}$ & $-3.27^{* * *}$ & $-2.53^{* *}$ & $-2.54^{* *}$ & -1.67 \\
County) & $(0.90)$ & $(0.82)$ & $(1.17)$ & $(1.06)$ & $(1.10)$ & $(1.11)$ \\
& -0.89 & -0.54 & -0.96 & & & \\
Constant & $(0.90)$ & $(0.92)$ & $(0.87)$ & & & \\
& & & & & & \\
Observations & -1.26 & -0.10 & -1.03 & -1.62 & -1.05 & -1.13 \\
Pseudo $R^{2}$ & $(1.08)$ & $(0.92)$ & $(1.04)$ & $(1.63)$ & $(1.44)$ & $(1.36)$ \\
\hline
\end{tabular}

Note. $\mathrm{HH}=$ household.

${ }^{*} p<.1 .{ }^{* *} p<.05 .{ }^{* * *} p<.01$.

Model 1 further predicts the odds of experiencing community stigma multiples by a factor of 1.5 when a woman living in a household with EVD case history rather than a home with no Ebola. The marginal effect of this relationship corresponds to a $30 \%$ increase in the odds that dependent variable of community stigma is true. Models 2 and 3 present different odds ratio modeling to better assess this relationship. Community stigma appears to correspond to higher odds with the independent variable of living in an EVD-affected household than with being a virus survivor.

\section{Family Stigma}

The difference in reported family stigma among women of EVD-affected homes (T2) and their peers was not significant, as referenced in Table 4. Yet reported frequency of stigmatization by family members was significantly higher amongst EVD survivors (T1) than non-EVD survivors (presented in Table 3). One in two female survivors in the study experienced family stigma. It should be mentioned that the sample size of survivors was low. The Ebola Survivors' Network-Liberia reports, however, often survivors were feared as possibly still being infectious even after discharge from an ETU and are blamed for being the root cause of the spread of the disease among the family, or being viewed as cursed which could spread through association (Glayweon \& Hanson, 2015).

Models 4-6 in Table 5 further explores logit modeling including fixed effects on interlocation (county) and holding all other variables constant to examine the effect of the independent variables of being 
an EVD survivor and/or living in an EVD-affected household (T2) on family stigma. If a person is an Ebola survivor, the odds of experiencing community stigma (versus no community stigma) increase by a factor of 3.23. However, the variable of being a survivor (T1) is statistically significant. Model 4 demonstrates that if a person is an Ebola survivor, the odds of experiencing family stigma (versus no family stigma) increase by a factor of 4.14. In other words, this model predicts that being a survivor versus never testing positive for Ebola corresponds to a $76 \%$ increase in the odds that the dependent variable of experiencing family stigma is true. Models 5 and 6 further test the potential relationships. Although they vary in their coefficients for the effect of being a survivor and living in an Ebola-affected household, the different models demonstrate similar pattern in odds-ratios.

\section{Psychosocial Stress Symptoms}

HIV/AIDS literature identifies the relationship between HIV-related stigma, increased depression, posttraumatic stress disorder, and risky behaviors in male and female populations, in the United States and Africa (Mahajan et al., 2008; Preston et al., 2007; Simbayi et al., 2007; Whetten et al., 2008). This fear of stigma comes at risk of affecting proper reporting based on individuals' attempts to minimize judgment from medical providers of how they or their family were infected as well as neighbors and family discovering their status (Valdiserri, 2002). Similarly, during the 2014 EVD crisis a common issue was reports of persons with possible symptoms not openly disclosing their health issues and incidents of EVD exposure to medical staff, not seeking treatment, or not cooperating with health policies, primarily out of fear of being labeled EVD-positive (Weyer, Blumberg, \& Paweska, 2014). One evaluation by Bellan, Pulliam, Dushoff, and Meyers (2014) recognized that survivors of symptomatic Ebola likely experienced psychosocial trauma or stigmatization, which may negatively affect their ability to perform if recruited for work positions. Additionally, qualitative research shows that ETU-discharged survivors also demonstrated distress during care (Rabelo et al., 2016). Yet limited research exists that demonstrates quantitative trauma rates in EVD-affected persons.

As most of the enumerators in the 2015 RESH study were social workers or trained PSS workers who were not monitored by clinician supervisors in field, they were not fully authorized to diagnose depression, posttraumatic stress disorder or other clinical symptoms. However, they were trained to identify symptoms listed on a MoH-authorized PSS scale for nonclinicians (Glayweon \& Hanson, 2015). There is similar research with tools that have been developed and commonly utilized to diagnosing post-traumatic stress for clinicians (Davidson et al., 1997; Foa, Cashman, Jaycox, \& Perry, 1997; Foa, Riggs, Dancu, \& Rothbaum, 1993). Common symptoms on the 2015 Liberian PSS scale included frequent sadness/crying, anger, withdrawal, worry/anxiety, nightmares, flashbacks, lack of energy, extensive violence, bad eating habits (lack of eating or overeating), lack of sleep, poor self-care (bathing, attention to health, etc.), and substance abuse (alcohol/drugs/smoking).

Enumerators asked each female adult if she had experienced each symptom after EVD entered her community and/or home. 
Hanson, Decosimo, \& Quinn, 2016

Table 6: Psychosocial Stress Symptoms (PSS) Among Female Adults Who Are Ebola Virus Disease (EVD) Survivors (T1) Compared to Female Peers in EVD-Affected Communities

\begin{tabular}{lccc}
\hline & Survivors (T1) & Peers & Difference \\
& $M, S E, S D$ & $M, S E, S D$ & $M, S E,[\mathrm{CI}]$, \\
Factor & {$[\mathrm{CI}], N$} & {$[\mathrm{CI}], N$} & $t$ Value, Cohen's $d$ \\
\hline Total PSS symptoms & $36 \%, 0.07,0.21$ & $23 \%, 0.01,0.17$ & $-13 \%^{* *}, 0.06,[-0.24,-0.01]$, \\
(average \% of all & {$[0.20,0.52], 9$} & {$[0.20,0.26], 135$} & $-2.22,-0.77$ \\
possible 12 & & & \\
symptoms) & & & \\
\hline
\end{tabular}

Note. CI = confidence interval.

${ }^{*} p<.1 .{ }^{* *} p<.05 .{ }^{* * *} p<.01$.

As shown in Table 6, the study participants who were EVD survivors (T1) suffered an average of 36\% of the 12 potential PSS symptoms; this is a significant difference of $13 \%$ more symptoms compared to their peers. Females from EVD-affected homes who never tested positive for Ebola (T2) also demonstrated high rates of PSS compared to their peers, yet this difference was not significant. EVD survivors had higher reported and demonstrated rates for nearly all individual PSS symptoms, some more than others. Symptoms that were most associated with surviving the disease include: poor eating habits, withdrawal, substance abuse and flashbacks.

The 67 noninfected heads of households affected by EVD (T2) did not demonstrate statistically significant differences in levels of psychosocial stress, including most individual PSS symptoms, compared to their study peers. The average noninfected female living in an EVD-affected home demonstrated $25 \%$ of all possible 12 symptoms, only $3 \%$ higher compared to their peers $(t=-0.97, p$ $<.40$, Cohen's $d=-0.16$ ). Sorrow, poor self-care, and low energy were moderately correlated with living in EVD-affected homes.

A 2015 statistical analysis in Guinea identified anorexia as common diagnosed symptom among EVD survivors as effects of the virus, not due to a lack of food but an indication of trauma (Qureshi et al., 2015). Yet poor eating habits (eating disorder) was also significant among survivors reported as a psychosocial stress indicator, including lack of eating/loss of appetite and overeating, which the evaluation clinicians attributed to stress eating. Further, Haddad and Gillespie (2001) state that eating disorders like anorexia are also identified as possible symptoms, which need to be additionally treated in persons with HIV/AIDS.

Like EVD, withdrawal is associated with positive HIV/AIDS status, yet it is often related to stigma affecting the individual, per Fife and Wright (2000). Additionally, there are prevalent rates of patients with HIV/AIDS who are also diagnosed with substance abuse and depression, yet this relationship is complex (Berger-Greenstein et al., 2007; Breitbart et al., 1997). It is culturally atypical for women to use substances such as alcohol in Liberia. The female survivors in the study who reported using alcohol and other substances admitted doing so after returning to their communities from ETU, and demonstrated a desire to indulge in at-risk behaviors like partying that they had not previously done before Ebola. 
Table 7: Ordinary Least Squares Regression Analysis of Average \% of Psychosocial Symptoms (PSS) Among Liberian Females Affected by Ebola Virus Disease (EVD)

\begin{tabular}{|c|c|c|c|c|c|}
\hline \multirow[b]{2}{*}{ Variable } & \multicolumn{5}{|c|}{ Average $\%$ of Total PSS } \\
\hline & Model 1 & Model 2 & Model 3 & Model 4 & Model 5 \\
\hline \multirow[t]{2}{*}{ EVD survivor } & $0.13^{*}$ & & 0.13 & $0.14^{*}$ & $0.16^{* *}$ \\
\hline & (0.07) & & $(0.08)$ & $(0.08)$ & $(0.08)$ \\
\hline \multirow[t]{2}{*}{ Living in EVD HH } & & 0.03 & $0.06^{*}$ & & $0.07^{* *}$ \\
\hline & & $(0.03)$ & $(0.03)$ & & $(0.03)$ \\
\hline \multirow[t]{2}{*}{ Age } & & & -0.00 & & \\
\hline & & & $(0.00)$ & & \\
\hline \multirow[t]{2}{*}{ Education } & & & -0.01 & & \\
\hline & & & $(0.01)$ & & \\
\hline \multirow[t]{2}{*}{ Working } & & & -0.00 & & \\
\hline & & & $(0.05)$ & & \\
\hline \multirow[t]{2}{*}{ Adult-child ratio } & & & $-0.04^{* * *}$ & $-0.03^{*}$ & $-0.03 * *$ \\
\hline & & & $(0.01)$ & $(0.01)$ & $(0.01)$ \\
\hline \multirow{3}{*}{$\begin{array}{l}\text { Interlocation } \\
\text { (County) }\end{array}$} & & & $-0.09 * * *$ & $-0.09 * * *$ & $-0.10^{* * *}$ \\
\hline & & & $(0.03)$ & $(0.03)$ & $(0.03)$ \\
\hline & & & $-0.17 * * *$ & $-0.15^{* * *}$ & $-0.17 * * *$ \\
\hline \multirow{3}{*}{ Constant } & & & $(0.04)$ & $(0.03)$ & $(0.04)$ \\
\hline & $0.23^{* * *}$ & $0.22 * * *$ & $0.40 * * *$ & $0.31 * * *$ & $0.28^{* * *}$ \\
\hline & $(0.01)$ & $(0.02)$ & $(0.08)$ & $(0.03)$ & $(0.03)$ \\
\hline Observations & 144 & 144 & 125 & 133 & 133 \\
\hline$R^{2}$ & 0.03 & 0.01 & 0.18 & 0.14 & 0.18 \\
\hline Adjusted $R^{2}$ & 0.0267 & 0.000 & 0.120 & 0.112 & 0.143 \\
\hline
\end{tabular}

Note. $\mathrm{HH}=$ household.

${ }^{*} p<.1 .{ }^{* *} p<.05 .{ }^{* * *} p<.01$.

Examining OLS modeling using fixed effects on inter-location including adult-child ratio, we regress the effect of being an EVD survivor and/or living in an EVD-affected home on the outcome of average percentage of listed/demonstrated PSS symptoms (presented in Table 7). Models 1-5 present various interpretations of the key independent variables on the outcome. For this analysis, we specifically examine Model 5 presenting the joint effect of two key dependent variables on the outcome of total percentage of psychosocial stress, holding adult-child ratio constant. Being a survivor of EVD is associated with a $16 \%$ increase in psychosocial stress, while living in an EVD-affected household increases stress by $7 \%$, for which both variables' differences are significant $\left(p<.05\right.$; Adjusted $R^{2}=$ $0.18)$.

However, the relationship between EVD disease status and living in a home that had members with positive EVD is complex in discerning between stress suffered because of surviving the status compared to caring for and losing family members to the disease, or the negative factors that these women face as a result of the outbreak. 
Hanson, Decosimo, \& Quinn, 2016

\section{Conclusions}

Female adults affected by EVD, both survivors of the virus and those living with others with the disease, face difficult experiences that can negatively impede their recovery. Health literature demonstrates that adults living with a disease such as HIV/AIDS often are at higher risks of caring for additional children than they normally would raise and have difficulty in earning a stable income sufficient to support their household (Cluver et al., 2007; Evans, 2005; Nyambedha et al., 2003). During the Ebola outbreak, government agencies and international development organizations worried that a person's disease status affected her ability to work. Yet the findings of this study demonstrate that while survivors and women in EVD-affected homes made less money and worked less on average, this difference was not statistically significant. The crisis made finding stable work and income difficult for most women regardless of their disease status. Many female heads of households shared the common concern of adequately providing for their families, such as feeding, clothing, and paying school fees.

Similarly, the concern that EVD affected persons were placed in the position to foster and raise more children due to their parents dying in the crisis is shown by the research findings to be not significant compared to normal households in former hot zones. There are some affected households where the number of adults to children was highly unbalanced. Living in homes where one or only a handful of adults are raising five or more children can have grave consequences in terms of stress on the adults, financial burdens, and the quality of care for their children. These households require special government support and tracking. Furthermore, women in affected households are much more likely to experience family and community stigma. EVD survivors experienced the greatest risks of being socially ostracized and blamed even after Ebola had left the community. The reality remains that female EVD survivors are often shunned and discriminated against after their physical recovery from the disease; indicating the need for individual special support services, as well as more community awareness and intervention programming in locations with reported survivors.

Research by Amuri, Mitchell, Cockcroft, and Andersson (2011) showed that with HIV/AIDS, stigma manifests itself on an individual, family, and community level. Ebola is comparable to this finding. Additional research has found that psychological trauma is disproportionately higher among men and women living with HIV when compared to the general population (Fellows, Spahr, Byrd, Mindt, \& Morgello, 2014). Psychological trauma responses due to trauma are likely to be expected after experiencing Ebola personally, within the home, or in the community (Shultz, Baingana, \& Neria, 2014). Trauma and stigma can cause both psychological and social harm to an individual. This harm can result in an increased risk for depression, anxiety, reduced self-esteem, decreased individual economic opportunities, and isolation (Amuri et al., 2011; Tsai \& Venkataramani, 2015).

If an individual receives limited to no mental health support after a significant traumatic event, they are at a high risk for life long deficiencies. Trauma memories and reactions do not simply go away with time. A diagnosis of HIV/AIDS has been associated with long-term depression disorders, anxiety disorders, and mood disorders (Feldman, Betts, \& Blausey, 2014). With the similarities of social stigma and psychological impact of HIV and Ebola, one could assume that an Ebola survivor has a higher chance of psychological disorders due to their exposure. Long-term care for Ebola survivors should emphasize mental health care as a priority. Due to limited clinicians and access to care, mental health support may be provided through building community awareness and education about trauma and Ebola, survivor support groups, and individual care with trained and local psychosocial support workers (Shultz et al., 2014). 
The literature review demonstrates that with infectious diseases such as HIV/AIDS, adults living with disease need supportive services to address the negative impacts that the disease inflicts in their households. This includes ongoing financial and program support, including mental health services. The importance of providing ongoing program support for heads of households affected by EVD and those in their keep, including children who lost one or more parents or caregivers will be critical cannot be forgotten after the recovery phase of the outbreak. The effects of the outbreak continue to play on in the lives of the survivors even as Ebola is eliminated from the region.

Persons affected by EVD often are discharged with high levels of trauma. This trauma brings about newly developed psychosocial stress symptoms, such as poor eating habits and withdrawal. Instead of being offered circumstances to recover, in many possible cases their trauma increased as they faced the bleak reality of piecing back together what remained of their former life, or forced to start their lives completely anew.

This study attempted to broaden understanding of the conditions and mental health of women affected by EVD, including their negative experiences, stigma, and psychosocial wellbeing. Monitoring and evaluation, and coordination of advocacy and support for survivors and affected households since the start of the outbreak has primarily been led through the continuous leadership of the Liberian MoH, MoGCSP, and the Ebola Survivors' Network. Yet more effort is clearly needed. Women in Liberia are often in vulnerable socio-economic states, which are compounded by emergencies like Ebola. The present study demonstrated numerous parallels between HIV/AIDS and Ebola. This research is one of the first of its kind, including a statistical analysis of an initial study of an EVD-affected population. More thorough future research will help improve understanding and causal generalizations of what EVD-affected persons face and how to best help them through advocacy and program services: before, during and after an outbreak. This study further demonstrated the need to draw upon literature on infectious diseases in order to better inform health and support services for victims of Ebola. While these results may prepare the health and response community for future EVD outbreaks, the present study also serves as a reminder of those victims who already exist and need ongoing support by key national agencies and the international development community.

\section{Limitations}

Because of previous trauma and negative experiences, it is a challenge to distinguish between PSS existing before and after the outbreak. To minimize reporting error, enumerators were trained and given procedures to better distinguish between experiences and feelings that occurred before and after Ebola. They asked participants for symptoms that developed (listed on the PSS scale) specifically after Ebola first entered their community/home. Any symptoms that existed before the community and home were a hot zone were recorded as likely not attributable to Ebola. As a second measure, enumerators triangulated for self-reported PSS symptoms through later randomly selecting listed symptoms and observed for those symptoms given observation criteria (e.g., for poor self-care, was there a picture of the person in better appearance than now, or did the person demonstrate poor hygiene such as strong body odor or unkempt hair). They also spoke with older household members who could verify whether these symptoms developed within the specified timeframe. If the symptoms could not be verified, then they were dropped from the individual scale assessment and not included in data entry. 
The present study examined adult-to-child ratios of participants' households to examine how the crisis may have burdened households with orphaned or vulnerable children due to EVD. Yet the study was unable to determine accurately the number of adopted children or children taken in because of the virus. There was a perception that survivors and households affected by virus had more nonbiological children than same-community households without Ebola. However, the study data only captured the total number of children verses adults in the house, and how many biological children that the participant had. It may not have adequately captured additional rates such as total adopted children or children who passed away from the virus.

When assessing daily income, the differences in incomes between groups appeared nonsignificant, yet there are indications that there is a potential validity error in how the survey captured income, as it is unclear whether respondents misunderstood what to report as net income. There was also a wide range in reported incomes across socio-economic status, which may misconstrue averages with outlier cases. Further investigation into income and working differences may be useful to better assess the assumption that positive EVD status lowers an individual's ability to work and their income.

The current study conducted an analysis at three tiers. The significance of the findings is weakened by the low number of survivor participants in the study compared to their peers; however, these data included the entire population of adult survivors in the EVD-affected communities included in this study and is not a random sample of survivors. Survivors in study sites were purposefully selected by the GoL for study. As suggested by Shadish, Cook, and Campbell (2002), the study also presented effect sizes and conservative statistical test results to account for the potential lack of statistical power to represent more transparently generalizations and irrelevancies issues. This emphasizes the need for further similar research on survivors using multiple methods to better inform causal generalizations.

Most persons infected by EVD died. Numerous EVD survivors hid their identity when admitted to ETUs or were never formally blood tested. The present study excluded any survivors whose status could not be confirmed by the government registry. Although the sample size of survivors is small, all known survivors in the study area were included in the study, and therefore assumptions of the statistical analyses were met. These findings should be interpreted with caution; however, establishing relationships between survivorship and quality of life in this population is pertinent for future research related to EVD survivors. Further, this study provides a foundation to understanding the differences in experiences for survivors versus noninfected people and to better understand quality of life for EVD survivors, which are extremely important in the aftermath of the Ebola outbreak and can help inform future research. Currently, other scientific research is being conducted primarily on EVD survivors with larger sample sizes, which will likely provide more informative findings on the status of survivors. 


\section{References}

Abramowitz, S. A., McLean, K. E., McKune, S. L., Bardosh, K. L., Fallah, M., Monger, J., \& Omidian, P. A. (2015). Community-centered responses to Ebola in urban Liberia: the view from below. PLOS Neglected Tropical Disease Journal, 9, e0003706.

Agusto, F. B., Teboh-Ewungkem, M. I., \& Gumel, A. B. (2015). Mathematical assessment of the effect of traditional beliefs and customs on the transmission dynamics of the 2014 Ebola outbreaks. Bio-Med Central Medicine Journal, 13, 1.

Alonzo, A. A., \& Reynolds, N. R. (1995). Stigma, HIV and AIDS: An exploration and elaboration of a stigma trajectory. Social Science \& Medicine,41, 303-315.

Amuri, M., Mitchell, S., Cockcroft, A., \& Andersson, N. (2011). Socio-economic status and HIV/AIDS stigma in Tanzania. AIDS Care Journal, 23, 378-382.

Bellan, S. E., Pulliam, J. R., Dushoff, J., \& Meyers, L. A. (2014). Ebola control: Effect of asymptomatic infection and acquired immunity. The Lancet, 384, 1499-1500.

Berger-Greenstein, J. A., Cuevas, C. A., Brady, S. M., Trezza, G., Richardson, M. A., \& Keane, T. M. (2007). Major depression in patients with HIV/AIDS and substance abuse. AIDS Patient Care and STDs, 21, 942-955.

Breitbart, W., Rosenfeld, B., Passik, S., Kaim, M., Funesti-Esch, J., \& Stein, K. (1997). A comparison of pain report and adequacy of analgesic therapy in ambulatory AIDS patients with and without a history of substance abuse. Pain Journal, 72, 235-243.

Brown, L., Trujillo, L., \& Mcintyre, K. (2001) Interventions to reduce HIV/AIDS stigma: What have we learned? Horizons Program, Tulane School of Public Health and Tropical Medicine, 1-31.

Chertow, D. S., Kleine, C., Edwards, J. K., Scaini, R., Giuliani, R., \& Sprecher, A. (2014). Ebola virus disease in West Africa: Clinical manifestations and management. New England Journal of Medicine, 371, 2054-2057.

Christie, A., Davies-Wayne, G. J., Cordier-Lasalle, T., Blackley, D. J., Laney, A. S., Williams, D. E., \& Ladner, J. T. (2015). Possible sexual transmission of Ebola virus: Liberia, 2015. Morbidity and Mortality Weekly Report, 64, 479-481.

Chughtai, A. A., Barnes, M., \& Macintyre, C. R. (2016). Persistence of Ebola virus in various body fluids during convalescence: evidence and implications for disease transmission and control. Epidemiology and Infection Journal, 144, 1652-1660.

Cluver, L., Gardner, F., \& Operario, D. (2007). Psychological distress amongst AIDS-orphaned children in urban South Africa. Journal of Child Psychology and Psychiatry, 48, 755-756.

Davidson, J. R., Book, S. W., Colket, J. T., Tupler, L. A., Roth, S., David, D., \& Davison, R. M. (1997). Assessment of a new self-rating scale for post-traumatic stress. Psychological Medicine Journal, 27, 153-160.

Davtyan, M., Brown, B., \& Folayan, M. (2014). Addressing Ebola-related stigma: Lessons learned from HIV/AIDS. Global Health Action Journal, 7, 50-68.

Deen, G. F., Knust, B., Broutet, N., Sesay, F. R., Formenty, P., Ross, C., \& Jambai, A. (2015). Ebola RNA persistence in semen of Ebola virus disease survivors: Preliminary report. New England Journal of Medicine. doi:10.1056/NEJMoa1511410 
Evans, R. M. (2005). Social networks, migration, and care in Tanzania: Caregivers' and children's resilience to coping with HIV/AIDS. Journal of Children \& Poverty, 11, 111-114.

Fellows, R. P., Spahr, N. A., Byrd, D. A., Mindt, M. R., \& Morgello, S. (2014). Psychological trauma exposure and co-morbid psychopathologies in HIV+ men and women. Psychiatry Research, $230,770-776$.

Feldman, M. B., Betts, D. J., \& Blausey, D. (2014). Process and outcome evaluation of an art therapy program for people living with HIV/AIDS. Art Therapy Journal, 31, 102-109.

Fife, B. L., \& Wright, E. R. (2000). The dimensionality of stigma: A comparison of its impact on the self of persons with HIV/AIDS and cancer. Journal of Health and Social Behavior, 40, 50-67.

Foa, E. B., Cashman, L., Jaycox, L., \& Perry, K. (1997). The validation of a self-report measure of posttraumatic stress disorder: The Posttraumatic Diagnostic Scale. Journal of Psychological Assessment, 9, 445.

Foa, E. B., Riggs, D. S., Dancu, C. V., \& Rothbaum, B. O. (1993). Reliability and validity of a brief instrument for assessing post-traumatic stress disorder. Journal of Traumatic Stress, 6, 459473.

Fowler, R. A., Fletcher, T., Fischer, W. A., Lamontagne, F., Jacob, S., Brett-Major, D., \& Ferri, M. (2014). Caring for critically ill patients with Ebola virus disease: Perspectives from West Africa. American Journal of Respiratory and Critical Care Medicine, 190, 733-737.

Glayweon, M., \& Hanson, J. (2015, May). Survivors' network survey summary report. Ebola Survivors' Network of the Ministry of Health-Liberia, Government of Liberia.

Goffman, E. (1963). Stigma: Notes on the management of a spoiled identity. London, United Kingdom: Penguin Publishing Inc.

Goeijenbier, M., Van Kampen, J. J., Reusken, C. B., Koopmans, M. P., \& Van Gorp, E. C. (2014). Ebola virus disease: A review on epidemiology, symptoms, treatment and pathogenesis. Netherlands Journal of Medicine, 72, 442-448.

Green, A. (2014). West Africa struggles to contain Ebola outbreak. The Lancet, 383 , 1196.

Haddad, L., \& Gillespie, S. (2001). Effective food and nutrition policy responses to HIV/AIDS: What we know and what we need to know. International Food Policy Research Institute, 31, 2-17.

Mahajan, A. P., Sayles, J. N., Patel, V. A., Remien, R. H., Ortiz, D., Szekeres, G., \& Coates, T. J. (2008). Stigma in the HIV/AIDS epidemic: a review of the literature and recommendations for the way forward. AIDS (London, England), 22, S67.

doi:10.1097/01.aids.0000327438.13291.62

Nyenswah, T., Fallah, M., Sieh, S., Kollie, K., Badio, M., Gray, A., \& Cordier-Lasalle, T. (2015). Controlling the last known cluster of Ebola virus disease: Liberia, January-February 2015. Morbidity and Mortality Weekly Report, 64, 500-504.

Nyenswah, T. G., Westercamp, M., Kamali, A. A., Qin, J., Zielinski-Gutierrez, E., Amegashie, F., \& Aberle-Grasse, J. M. (2014). Evidence for declining numbers of Ebola cases: Montserrado County, Liberia, June-October 2014. Morbidity and Mortality Weekly Report, 63, 1072-1076.

Nyambedha, E. O., Wandibba, S., \& Aagaard-Hansen, J. (2003). Changing patterns of orphan care due to the HIV epidemic in western Kenya. Journal of Social Science \& Medicine, 57, 301305. 
OECD Development Centre. (2015). Social Institutions and Gender Index, Liberia. Retrieved from http://genderindex.org/sites/default/files/datasheets/LR.pdf

Preston, D. B., D'augelli, A. R., Kassab, C. D., \& Starks, M. T. (2007). The relationship of stigma to the sexual risk behavior of rural men who have sex with men. AIDS Education \& Prevention, 19, 218-219, 227-228.

Qureshi, A. I., Chughtai, M., Loua, T. O., Kolie, J. P., Camara, H. F. S., Ishfaq, M. F., \& Beavogui, K. (2015). Study of Ebola virus disease survivors in Guinea. Clinical Infectious Diseases, 61, $1035-1042$.

Rabelo, I., Lee, V., Fallah, M. P., Massaquoi, M., Evlampidou, I., Crestani, R., Severy, N. (2016). Psychological distress among Ebola survivors discharged from an Ebola treatment unit in Monrovia, Liberia: A qualitative study. Frontiers in Public Health, 4, 142.

Renewed Energy Serving Humanity (RESH). (2015). Playing to Live Program Baseline Evaluation Study. Monrovia, Liberia: United Nations Children's Fund.

Shadish, W. R., Cook, T. D., \& Campbell, D. T. (2002). Experimental and quasi-experimental designs for generalized causal inference. Belmont, CA: Houghton, Mifflin, and Company.

Shultz, J. M., Baingana, F., \& Neria, Y. (2014). The 2014 Ebola outbreak and mental health. JAMA: The Journal of the American Medical Association, 10032, 2014-2015.

Simbayi, L. C., Kalichman, S. C., Strebel, A., Cloete, A., Henda, N., \& Mqeketo, A. (2007). Disclosure of HIV status to sex partners and sexual risk behaviours among HIV-positive men and women, Cape Town, South Africa. Sexually Transmitted Infections Journal, 83, 29-34.

Stoskopf, C. H., Kim, Y. K., \& Glover, S. H. (2001). Dual diagnosis: HIV and mental illness, a population-based study. Community Mental Health Journal, 37, 469-479.

Toral, A. (2012, April). History of violence: Struggling with the legacy of rape in Liberia. Time Magazine. Retrieved from http://world.time.com/2012/04/30/history-of-violence-strugglingwith-the-legacy-of-rape-in-liberia/

Tsai, A. C., \& Venkataramani, A. S. (2015). The causal effect of education on HIV stigma in Uganda: Evidence from a natural experiment. Social Science Medicine Journal, 142, 1-19.

United Nations Development Programme. (2015). Human Development Report: Liberia. Retrieved from http://hdr.undp.org/en/countries/profiles/LBR

Valdiserri, R. O. (2002). HIV/AIDS stigma: An impediment to public health. American Journal of Public Health, 92, 341-342.

Weyer, J., Blumberg, L. H., \& Paweska, J. T. (2014). Ebola virus disease in West Africa: An unprecedented outbreak. SAMJ: South African Medical Journal, 104, 555-556.

Whetten, K., Reif, S., Whetten, R., \& Murphy-McMillan, L. K. (2008). Trauma, mental health, distrust, and stigma among HIV-positive persons: Implications for effective care. Journal of Psychosomatic Medicine, 70, 531-538. 
The Journal of Social, Behavioral, and Health Sciences is an open-access, peer-reviewed, online interdisciplinary journal focusing on research findings that address contemporary national and international issues. Its objectives are to (a) encourage dialogue between scholars and practitioners in the social, behavioral, and health sciences that fosters the integration of research with practice; (b) promote innovative models of interdisciplinary collaboration among the social, behavioral, and health sciences that address complex social problems; and (c) inform the relationship between practice and research in the social, behavioral, and health sciences.

Walden University Publishing: http://www.publishing.waldenu.edu 